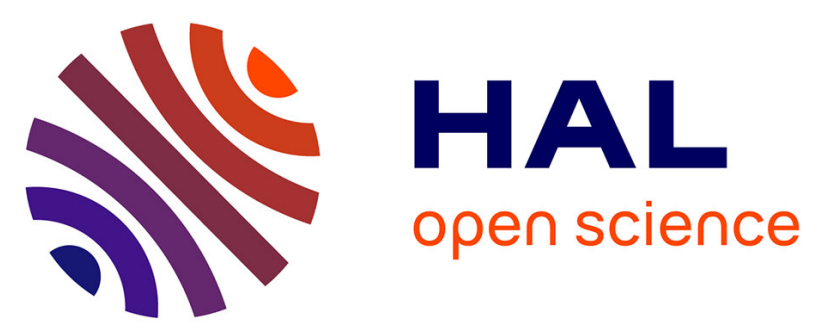

\title{
Organic ultrathin film adhesion on compliant substrate using scratch test technique
}

Xavier Boddaert, Grégory Covarel, Bassem Ben Saïd, Mylene Mattei, Patrick Benaben, Jérôme Bois

\section{- To cite this version:}

Xavier Boddaert, Grégory Covarel, Bassem Ben Saïd, Mylene Mattei, Patrick Benaben, et al.. Organic ultrathin film adhesion on compliant substrate using scratch test technique. Thin Solid Films, 2012, 10.1016/j.tsf.2012.07.138 . emse-00768611

HAL Id: emse-00768611

https://hal-emse.ccsd.cnrs.fr/emse-00768611

Submitted on 22 Dec 2012

HAL is a multi-disciplinary open access archive for the deposit and dissemination of scientific research documents, whether they are published or not. The documents may come from teaching and research institutions in France or abroad, or from public or private research centers.
L'archive ouverte pluridisciplinaire HAL, est destinée au dépôt et à la diffusion de documents scientifiques de niveau recherche, publiés ou non, émanant des établissements d'enseignement et de recherche français ou étrangers, des laboratoires publics ou privés. 
Organic ultrathin film adhesion on compliant substrate using scratch test technique

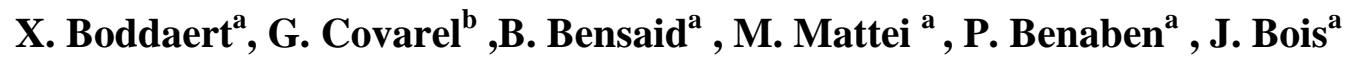 \\ ${ }^{\text {a }}$ Ecole Nationale Supérieure des Mines de Saint Etienne, Centre de Microelectronique de \\ Provence Georges Charpak, 880 route de Mimet, 13120 Gardanne, Cedex, France \\ ${ }^{\mathrm{b}}$ Université de Haute Alsace (UHA), Laboratoire Physique et Mécanique Textile (LPMT), \\ EA 4365, F-68093 Mulhouse, France
}

Corresponding author: Xavier Boddaert

Full mailing adress: Ecole Nationale Supérieure des Mines de St Etienne Centre de Microélectronique de Provence - Georges Charpak 880 Avenue de Mimet 13541 Gardanne Cedex France

Telephone: +33442616761

Fax : +33442616593

e-mail : boddaert@emse.fr 


\begin{abstract}
:
The mechanical properties of interfaces and more precisely the adhesion are of great importance to understand the reliability of Organic Thin Film Transistor (OTFT) on compliant substrate. Since these devices are flexible, they will undergo a lot of mechanical stress during their useful life. Many adhesion test techniques have been developed to measure adhesion energy of thin films but they are hard to implement in the case of submicronic organic thin film deposited on flexible substrate. Recently, the feasibility and repeatability of the scratch test technique as a tool for testing the adhesion and the damage behaviour of ultrathin film on polymeric substrate have been demonstrated. However, direct comparison of critical load between samples was not straightforward since different failure mechanisms were induced. In the present work, we have performed nanoscratch experiments on submicron thin film deposited on flexible substrate. The use of a tip radius of $5 \mu \mathrm{m}$ enabled to induce a unique delamination mechanism by localizing and maximizing the stress closer to the interface. We have observed an increase of the critical load on samples processed with an adhesive plasma treatment prior to thin film deposition; confirming the effectiveness of this treatment. We have also performed mechanical ageing tests on specimens and proved that the scratch test technique is sensitive enough to monitor the degradation of the interface properties. Finally, we have discussed some existing energy models. Taking into account some limitations, Laugier's model gives an upper bound of adhesion energy.
\end{abstract}

Keywords: nanoscratch; adhesion; flexible substrate; organic electronics; thin layer; delamination

\title{
1. Introduction
}

A large amount of efforts has been devoted to the design and development of printed electronics on flexible substrate to achieve low cost, large area flexible electronics [1]. The 
manufacturing process consists in the deposition of active thin layers and electrodes on a plastic substrate using different printed techniques like serigraphy, flexography and inkjet printing. Electrical characteristics and stability in ambient air have reached attractive performances [2,3]. Since these devices are flexible, they will face, during their useful life, a lot mechanical strains and stresses. Consequently, the investigation of the mechanical properties of the interfaces and the evaluation and improvement of the adhesion are essential to ensure the stability and reliability of the devices.

Many adhesion test techniques have been developed to measure adhesion energy of thin films but they are hard to implement in the case of submicronic organic thin film deposited on flexible substrate. The peel test is used in a variety of configurations, in which a thin strip is pulled away at some angle from the underlying substrate. Although the peel test offers simple test geometry for measuring adhesion strength [4,5], in the case of organic thin layers, the coating may tear due to the high stresses at the contact with the mechanical grips [6]. The pull-test allows a quantitative adhesion measurement, in which strain or energy can be extracted [7], but it still suffers from several problems like the adhesive compatibility [8]. Others specific adhesion test techniques have been developed like cross section indentation [9], four point bending [10], tensile loading [11] or blister adhesion test [12,13]. However, these methods require coating thickness of about several hundred $\mu \mathrm{m}$, rigid substrate and difficult sample preparations, respectively. In a previous paper, we have tested the scratch test technique on thin organic layers printed on Poly Ehylen Naphtalat (PEN) flexible substrate and demonstrated the feasibility, reproducibility and sensitivity of this technique [14]. However, direct comparison of critical load between samples was not straightforward since different failure mechanisms were induced.

The objective of this work is to improve the scratch test experimental conditions to get more quantitative results. We did nanoscratches on a thin perfluoropolymer layer deposited on PEN substrate, studied the influence of scratch speed on damage mechanism and discussed the 
effect of the tip radius. Then, we performed mechanical ageing tests and investigated the degradation of the interface properties. Finally, we discussed existing energy models and computed an adhesion energy.

\section{Experimental details}

One type of specimen has been used. It consisted of a single thin layer deposited on a $125 \mu \mathrm{m}$ thick Teonex ${ }^{\circledR}$ Poly Ethylen Naphtalat (PEN) semicrystalline polymeric substrate. The substrate was obtained after a lamination process inducing anisotropic properties. Young's Modulus was specified by DuPontTeijinFilms ${ }^{\mathrm{TM}}$, at 5060 and $6240 \mathrm{MPa}$ for parallel and perpendicular directions to the laminating direction, respectively and the Poisson ratio at 0.4 . A $800 \mathrm{~nm}$ thick perfluoropolymer dielectric layer [15] was deposited on PEN by spin coating, using a SCS 6800 spin coater apparatus, at room temperature at $2000 \mathrm{rpm}$. The substrate size in the deposition process was $10 \times 10 \mathrm{~cm}^{2}$. Two deposition conditions were studied with and without plasma treatment prior to coating deposition. The plasma treatment, performed by means of a RIE Oxford Instrument Plasmalab apparatus, consists in a rapid reactive ion etch using $\mathrm{O}_{2}$ and $\mathrm{SF}_{6}$ gases, in order to improve the wettability of PEN surface [16]. The layer presents a glass transition temperature above $100^{\circ} \mathrm{C}$ preventing any change of structure during measurements. The layer thickness has been set to optimize the electrical performances of the OTFT [17].

The adhesion properties were evaluated at room temperature using a Nano Indenter® XP system. The scratch indenter was a diamond Rockwell C stylus with a spherical tip having a radius of $5 \mu \mathrm{m}$. The value of the Young's modulus and Poisson ratio were specified at 1050 GPa and 0.20 respectively [18]. The scratch length has been set to $1 \mathrm{~mm}$. Two different speeds were tested: 10 and $100 \mu \mathrm{m} . \mathrm{s}^{-1}$. A typical scratch experiment is performed in three stages; an original profile, a scratch segment and a residual profile. In the original profile, 
surface morphology is obtained by pre-profiling the surface under a very small load of $100 \mu \mathrm{N}$. During the scratch segment, the applied load was progressively increased from 0 to $30 \mathrm{mN}$. The indenter actual penetration depth under the sample surface is estimated by comparing the indenter displacement normal to the surface during the scratching, with the topography of the original surface at each position along the scratch length. Finally a postprofile at a normal load of $100 \mu \mathrm{N}$ establishes residual scratch depth. Thus, the variations of the indenter penetration and residual depth are recorded as a function of the normal load. A sensor enables the measurement of the tangential force allowing the estimation of the friction coefficient. For statistical purpose, ten measurements, parallel to the substrate lamination direction, were performed at room temperature on each sample. After the test, the critical load (Lc) where failure occurred in a particular mode was determined by post-mortem observation of the scratch track using optical and SEM microscopes. The error on the Lc determination includes the sample preparation, the accuracy and the stability of the nanoscratch equipment and the exact location of the beginning of the damage. Since statistical errors represent the major contribution, scattering given below corresponds to the standard deviation. Scanning Electron Microscopy (SEM) was performed using a CARL ZEISS-Ultra 55 apparatus and elemental analyses were carried out by Energy-Dispersive X ray (EDX) using an OXFORD INCA system.

Fatigue tests have been performed at room temperature using a dedicated cyclic bending machine. The procedure was similar to that detailed elsewhere [19]. Cyclic stresses were performed at 15 cycles per minute by rolling the flexible specimen on a $5 \mathrm{~mm}$ radius cyclinder, corresponding to a bending strain of $1.25 \%$. Before the fatigue sequence, scratch tests have been performed to determine the initial critical load. Then, the mechanical stability of the interface has been monitored by scratch test measurements done after 1000, 5000, 9000 and 10000 cycles. 
3. Results and discussion

3.1 Description of the damage mechanism: influence of the scratch speed and plasma treatment

The damage sequence, obtained at $10 \mu \mathrm{m} . \mathrm{s}^{-1}$, of the perfluoropolymer coating deposited on PEN with plasma treatment is presented in figure 1. There is a small amount of deformation observed under low load and stress level since only the wake of the indenter is observed. This is due to fully recoverable elastic deformation, time dependent viscoelastic deformation and a small amount of non recoverable plastic deformation resulting from compressive indentation [20].When the load increases, lateral pads are more pronounced as seen in figure 1-a. Then, a large delamination of the coating is observed, which spreads in diamond shape widely outside the scratch track (fig.1-e, fig.1-f). A plastic deformation of the substrate under the indenter is still visible at the beginning of the delamination area (fig1-b) but as the load increases, the scratch track on the substrate becomes blurred (fig1-c and d).

Figure 1

An EDX elemental analysis, presented in figure 2, was performed at the beginning of the delamination area. It reveals that fluorine, constituent of the coating, is present outside the delaminated area (point 3) but is no longer detected inside (points 1 and 2), showing an adhesive damage at the interface between the coating and the substrate.

Figure 2 
The penetration and residual depths are both plotted as a function of the scratch length in figure 3. At the beginning of the scratch, the indenter regularly sinks into the material. When the load increases the penetration depth slope is steeper, evidencing the onset of the delamination. The residual depth, determined at $100 \mu \mathrm{N}$ normal load, takes into account the elastic recovery of the material. The first part of the track is clearly visible, the plastic deformation increases progressively up to the delamination occurrence (see arrow in fig.3). Then, the residual depth is nearly constant at about $800 \mathrm{~nm}$, corresponding to the coating thickness. This observation is in good agreement with the lower plastic deformation of the substrate shown at higher load on SEM pictures in fig1-c and d.

Figure 3

During the scratch, compressive stresses are generated ahead of the indenter and tensile stresses are induced behind the indenter [21]. Therefore it is possible to describe the delamination mechanism. A crack is initiated by tensile stresses at the coating surface on the rear side of the contact between the indenter and the coating [22]. This crack, in the case of a pure indentation test, is not able to propagate through the whole coating thickness due to the existence of compressive stresses on the opposite side of the coating [22]. But, in the present case, the crack is able to open under the tip motion and friction effects and propagate towards the interface, initiating the delamination mechanism. Thus, the film is torn and as the indenter moves forward, part of the coating is wedged between the indenter and the substrate. The coating is then compressed in front of the indenter and the shear stresses induce the lifting of the coating and the delamination just ahead of the tip, so that the superficial layer is accumulated in front of the indenter. Moreover, part of the removed coating may progressively accumulate under the indenter. As a consequence, the stress is reduced at the 
substrate surface. This is confirmed by the change of the slope, visible at about $800 \mu \mathrm{m}$ on the penetration depth curve in figure 3 . Hence, the plastic strain of the substrate is very low.

Table 1

Scratch test measurements were performed at $100 \mu \mathrm{m} . \mathrm{s}^{-1}$ on the same specimen and at both speeds, on the specimen elaborated without plasma treatment. In each case, the same damage sequence is observed. As a consequence, the critical load corresponding to the beginning of the delamination is considered as relevant to evaluate the adhesion properties. Mean critical loads are reported in table 1 . The repeatability is quite good as indicated by the low standard deviations. Moreover the delamination appears at higher critical loads when a plasma treatment is done before the perfluoropolymer thin film deposition, indicating the improvement of the adhesion. The specimen processed without plasma treatment is more sensitive to the scratch speed. The influence of the scratch speed on mechanical properties was exhaustively studied in the case of polymer systems by Barletta et al. [23] for speed ranging between $0.2 \mathrm{~mm} \cdot \mathrm{min}^{-1}$ and $100 \mathrm{~mm} \cdot \mathrm{min}^{-1}$. They observed variations of deformation contributions, namely elasticity, plasticity and fracture expressed in terms of the three response model [24], as a function of the speed. They pointed out that elasticity is not sensitive to the speed all over the studied range. Plasticity remains constant for scratch speeds between $1 \mathrm{~mm} \cdot \mathrm{min}^{-1}$ and $20 \mathrm{~mm} \cdot \mathrm{min}^{-1}$. Above $20 \mathrm{~mm} \cdot \mathrm{min}^{-1}$, plasticity decreases and fracture is promoted while below $1 \mathrm{~mm} \cdot \mathrm{min}^{-1}$, plasticity increases and the fracture contribution is reduced. In the present case, the lower speed $\left(10 \mu \mathrm{m} . \mathrm{s}^{-1}\right)$ corresponds to $0.6 \mathrm{~mm} \cdot \mathrm{min}^{-1}$ and the higher speed $\left(100 \mu \mathrm{m} . \mathrm{s}^{-1}\right)$ to $6 \mathrm{~mm} \cdot \mathrm{min}^{-1}$. The increase of critical loads with the scratch speed is due to viscoelastic effects combined with a reduction of the plasticity and an increase of the fracture contributions for the studied system. 
In a previous paper [14], scratch measurements, done with a $200 \mu \mathrm{m}$ tip, have shown different damage behaviours according to the plasma treatment. Without plasma treatment, delamination is observed whereas only cohesive localized damages are generated on samples with plasma treatment. The influence of tip radius on stress distribution in the pure elastic approximation (Hertzian contact) during an indentation test has been studied by numerous authors on various materials $[22,25,26]$. The maximum stress is closer to the surface when the tip radius is smaller. In addition, for a given normal load, the intensity is higher for a smaller tip radius. Hence the stress in the coating is much lower when scratch tests are performed with a $200 \mu \mathrm{m}$ radius tip; leading to more cohesive damages because stresses are not high enough to induce a delamination process.

\subsection{Mechanical Ageing}

We performed bending cyclic tests and check the mechanical stability of the interface using the scratch test technique. Scratch tests have been done at $10 \mu \mathrm{m} . \mathrm{s}^{-1}$ after $1000,5000,9000$ and 10000 cycles on samples without plasma treatment. The same delamination mechanism is observed for each measurement so that the determination of the critical loads was considered as relevant to evaluate the mechanical strength of the layer on the substrate. In addition, the

friction coefficient was recorded during each scratch. They are both plotted in figure 4. A decrease of the critical load and friction coefficient as a function of the number of bending cycles is observed, indicating a degradation of the adhesion.

Figure 4 
Numerous authors have focussed great interest on adhesion energy determination. Models depend on the failure mode involved during the scratch. For instance Malzbender, [27] and Thouless [28] described models usable when an extensive spalling occurs ahead of the indenter. Malzbender assumed a disk sector shape chipping and tested it on organic-inorganic coating deposited on glass [27], whereas Thouless considered trapezoidal spallation. However, these approaches are not in agreement with the damage sequence observed in the present work. Laugier [29] has proposed an energy approach of the coating adhesion which has been successfully applied to various systems. It consisted in an analytical calculation based both on Hertz theory and on sliding spherical indenter. The work of adhesion to debond a length $\Delta \mathbf{x}$ of interface is given by:

$$
\mathbf{W}=\frac{\sigma^{2} \mathbf{h}}{2 \mathbf{E}}(1)
$$

where $\mathrm{h}$ is the coating thickness, $\mathrm{E}$ its Young's modulus, $\sigma$ the applied stress at the leading edge of the coating written as followed:

$$
\sigma=\frac{\mathbf{P}}{2 \pi \mathbf{a}^{2}}\left[\left(4+v_{1}\right) \frac{3 \pi \mathbf{f}}{8}-\left(1-2 v_{1}\right)\right](2)
$$

In this expression, $\mathrm{P}$ is the applied load, $\mathrm{f}$ the coefficient of friction between the indenter and the coating and $v_{1}$ is the Poisson ratio of the substrate.

The radius of the contact circle is given by the Hertz formula [30]:

$$
\mathbf{a}^{3}=\frac{3}{4} \mathbf{P R}\left(\frac{1-v_{1}^{2}}{\mathbf{E}_{1}}+\frac{1-v_{2}^{2}}{\mathbf{E}_{2}}\right)
$$

where $\mathrm{R}$ is the radius tip, $v_{1}$ and $v_{2}$ are the Poisson ratios of the substrate and indenter respectively and $E_{1}$ and $E_{2}$ are the Young's moduli of the substrate and indenter respectively. This calculation is usable either for ductile metallic or brittle coating providing that the coating removal process is described in terms of interfacial shear force. In addition, deadhesion must be considered to occur when a critical load is reached. Moreover, the coating must be under compression when the removal occurs ahead of the indenter. So, the region 
ahead of the indenter can reduce its energy by expanding and lifting from the substrate when the energy stored in this region is sufficient to provide both the work needed to deform the coating elastically and the work necessary for the coating detachment. In this model, Laugier assumes that the energy expended in deforming a ductile coating is a small fraction of the work of adhesion. Once the detachment is initiated, plastic stretching ensues following the passage of the indenter and with at most a small increase in load, tearing and complete removal occur. The description of the damage sequence observed in the present work is in fair agreement with the damage mechanisms described by Laugier. Nevertheless, Laugier pointed out that the elastic condition must prevail in the contact region and in the region ahead of the indenter at the onset of the removal process. Since in our case, before delamination, a plastic deformation of the coating is observed (see figure 2) and the elastic deformation of the substrate has been neglected, the adhesion energies calculated in the following should only be considered as an upper bound.

Figure 5

Adhesion energies were calculated by means of equations (1), (2) and (3) assuming a residual stress free coating [29]. They are plotted as a function of bending cycles in figure 5. The adhesion energy of the as-deposited specimen is about $39 \mathrm{~J} . \mathrm{m}^{-2}$. When the number of cycles increases, the adhesion energy progressively decreases down to $2 \mathrm{~J}_{\mathrm{m}} \mathrm{m}^{-2}$ for 10000 cycles. These values are in the range between Van der Walls adhesion and cohesive damage of polymers [31]. The as-deposited value is closed to the one obtained by Le Houerou et al. for a thermoset polymer coating on polycarbonate substrate [31]. The adhesion strength decrease can be due to a change of the substrate or the coating mechanical properties. Further mechanical characterizations are in progress to understand the origin of such a decrease. This 
will be useful to get a better understanding of the variations of the electrical characteristics observed on organic thin film transistors stressed in the same way [19].

\section{Conclusion}

The present paper reports adhesion strength investigations of perfluoropolymer thin layer on PEN substrate using scratch test measurements. The use of a suitable tip radius enables to induce an unique damage mechanism. The evolution of critical loads give crucial informations on adhesion strength. Particularly the method has proven to be sensitive enough to highlight the effect of a plasma treatment prior to thin film deposition and to monitor the variations of the adhesion strength according to fatigue cycling tests. The use of Laugier's model led only to the determination of an upper bound of adhesion energy, consistent with the literature.

\section{References}

[1] T. Someya, T. Sekitani, M. Takamiya, T. Sakurai, U. Zschieschang, and H. Klauk, "Printed organic transistors : Toward ambient electronics," Quantum, 2009, pp. 4-6.

[2] J. E. Anthony, M. Heeney, B.S. Ong, MRS Bull. 33 (2008) 698-705.

[3] J.M. Verilhac, M. Benwadih, A.L. Seiler, S. Jacob, Organic Electronics 11 (2010) 456562.

[4] A. N. Gent, G. R. Hamed, J. of Appl. Polym Sci. 21 (1977) 2817-2831.

[5] M. D. Thouless, H. M. Jensen, J. of Adhesion 38 (1992) 185-197. 
[6] Y. H. Lai, D. A. Dillard, J. of Adhesion 56 (1996) 59-78.

[7] C. T. Sun, W. Qian, Int. J. Solids Struct. 34 (1997) 2595-2609.

[8] H. Yu, J.W. Hutchinson, Thin Solid Films 423 (2003) 54-63.

[9] J. Lesage, P. Demarecaux, O. Bartier, G. Mesmacque, Revue de Métallurgie, 90, 12 (1993) 1655-1663.

[10] R. H. Dauskardt, M. Lanea, Q. Mab and N. Krishnac, Engineering Fracture Mechanics 61 (1998) 141-162.

[11] H-J. Kim, M-W. Moon, D-I. Kim,K.-R Lee, K.-H. Oh, Scripta Mater. 57 (2007) 10161019.

[12] H.M. Jensen, M.D. Thouless, Int. J. Solids Struct. 30 (1993) 779-795.

[13] Y. H. Lai, D. A. Dillard, J. Adhesion Sci. Technol. 8 (1994) 663-678.

[14] G. Covarel, B. Bensaid, X. Boddaert, S. Giljean, P. Benaben, P. Louis, Surf. Coat. Technol, (2011) DOI:10.106/j.surfcoat.2011.09.057 in press

[15] T. Umeda, D. Kumaki, S. Tokito, Organic Electronics 9 (2008) 545-549.

[16] D. Hegemann, H. Brunner, C. Oehr, Nucl. Instr. and Meth. in Phys. Res. B 208 (2003) 281-286.

[17] D. Boudinet, M. Benwadih, S. Altazin, R. Gwoziecki, J.M. Verilhac, R. Coppard, Organic Electronics 11 (2010) 291-298.

[18] N. Savvides, T.J. Bell, Thin Solid Films, Vol 228 (1993), 289-292

[19] X. Boddaert, B. Bensaid, P. Benaben, R. Gwoziecki ,R. Coppard Microelectronics Reliability 50(2010) 1884-1887.

[20] H. Jiang, R. Browning, H.- J. Sue, polymer 50 (2009) 4056-4065.

[21] V. Jardret, P. Morel, Progress in Organic Coating, 48 (2003) 322-331.

[22] A. Abdul-Baqi, E. Van der Giessen, Int. J. of Solids Structures 39 (2002) 1427-1442.

[23] M. Barletta, A. Gisario, L. Lusvarghiu, G. Bolleli, G. Cubino, Appli. Surf. Sci. 254 (2008) 7198-7214.

[24] W. Shen, C. Ji, F. N. Jones, M. P. Everson, R. A. Ryntz, Polym Mater.Sci.Eng. 74 (1996) 346. 
[25] W.G. Mao, Y.G. Shen, C. Lu, Scripta Materilia 65 (2011) 127-130.

[26] Chung-Jen Lu, D. B. Bogy, Int. J. Solids Structures, 32 ,12 (1995) 1759-1770.

[27] J. Malzbender, G. de With, Surf. Coat. Technol. 154 (2002) 21-26.

[28] M. D. Thouless, Eng. Frac. Mechanics, 61 (1998) 75-81.

[29] M.T. Laugier, Thin Solid Films, 117 (1984) 243-249.

[30] S. Timoshenko and J.N. Goodier, Mc Graw_Hill, New York 1951.

[31] V. Le Houerou, C.Gauthier, R. Schirrer, Tribology International 43 (2010) 129-135. 